\title{
CONTAMINACIÓN DE SEDIMENTOS DEL RIO ANOIA POR METALES PESADOS (BARCELONA - ESPAÑA)
}

\section{Hermógenes Rosas Rodríguez}

\section{RESUMEN}

El estudio de la contaminación por metales pesados de los sedimentos del río Anoia tiene un interés particular por cuanto el agua de ese río es aprovechada para el consumo humano en el área metropolitana de Barcelona. El monitoreo ambiental realizado en este trabajo, tiene como objetivo principal permitir la evaluación del grado de contaminación para determinar el sistema de tratamiento más eficiente para su potabilización. Para este estudio se establecieron cinco puntos de muestreo, las muestras de los sedimentos se recogieron durante un año con una frecuencia trimestral y se tomaron a nivel del agua. La extracción de los metales en sedimentos se llevó a cabo mediante digestión ácida con $\mathrm{HNO}_{3}$ y $\mathrm{HCl}$, utilizando recipientes de Pyrex cerrados. Los contenidos metálicos en los sedimentos se determinaron por (ICP-MS) ELAN 6000.

Las concentraciones de los metales que superan los valores permisibles en la legislación son el Hg y Cr en Vilanova del Camí, punto de muestreo del estudio con índices de contaminación elevados. Asimismo, están sensiblemente contaminados por el Cu los puntos de muestreo de Vilanova del Camí, Sant Sadurní d'Anoia y Martorell-A, y por el Ni la mayoría de los puntos de muestreo. De forma general, se puede indicar también que los metales pesados que se han analizado presentan un incremento metálico generalizado en los sedimentos por causas antropogénicas. El incremento es de treinta y cuatro veces en $\mathrm{Cr}$, treinta y uno en $\mathrm{Hg}$, cinco en $\mathrm{Sb}$, cuatro en $\mathrm{Zn}$, tres en $\mathrm{Cd}$, dos veces y media en $\mathrm{Cu}$ y $\mathrm{Pb}$ y, una vez y media para el Ni. Por el contrario, para el As el promedio medio es inferior a la concentración basal (niveles de fondo), lo que hace pensar que su principal origen es litogénico.

Palabras Clave: Sedimentos, Metales Pesados, Río, Industrias, Componentes Principales. 